\title{
INOVAÇÃO A SERVIÇO DE UM JUDICIÁRIO TRANSFORMADOR: UMA PERSPECTIVA SISTÊMICA
}

INNOVATION FOR A TRANSFORMATIVE JUDICIARY: A SYSTEMIC PERSPECTIVE

TAIIS SCHILLING FERRAZ Desembargadora federal no TRF4. Doutora em ciências criminais e mestre em direito pela PUCRS. Membro do corpo docente permanente do PPGPD/Enfam. Integrante do Grupo Operacional do Centro Nacional de Inteligência da Justiça

Federal. https://orcid.org/0000-0002-9592-0488

LUCIANE AMARAL CORRÊA MÜNCH Desembargadora federal no TRF4. Corregedora da Justiça Federal da 4ํㅡ Região. Doutora em direito pela Universidade de Genebra. Mestre em direito pela PUCRS. LLM pela LSE. Membro do corpo docente permanente do PPGPD/Enfam. https://orcid.org/0000-0002-5984-2769

\section{RESUMO}

O artigo trata da inovação no âmbito do Poder Judiciário, identificando elementos e dimensões a serem considerados para que os processos de inovação se qualifiquem como responsáveis. Busca base teórica na filosofia da inovação e no pensamento sistêmico. Partindo dos conceitos de inovação e de valor público e construindo uma definição para a inovação no contexto do Poder Judiciário, apresenta os condicionantes da inovação responsável e a perspectiva sistêmica a ser observada, propondo, ao final, uma estrutura de referência para os processos de inovação, em que a adequação ao propósito institucional e a atenção aos impactos sistêmicos permeiem todo o processo.

Palavras-chave: inovação responsável; perspectiva sistêmica; impactos.

\section{ABSTRACT}

This article deals with innovation in the Judiciary Power, identifying elements and dimensions to be considered for innovation processes to 
qualify as responsible. It is based on critical philosophy of innovation and systems thinking. Setting out from the concepts of innovation and public value and building a concept of innovation for the Judiciary Power, it presents the conditions for responsible innovation and the systemic perspective to be followed in innovation processes. Finally, it offers a reference framework for innovation processes, oriented by institutional purposes and attention to the systemic impacts of the innovation, which permeates the whole process.

Keywords: responsible innovation; systemic perspective; impacts.

Recebido: 28-5-2021

Aprovado: 28-6-2021

\section{SUMÁRIO}

1 Introdução. 2 O que significa inovar? 3 Inovar é sempre bom? 4 Inovação responsável. 5 Inovando em perspectiva sistêmica. 6 A espiral da inovação no Poder Judiciário. 7 Desenhando a espiral de inovação no Poder Judiciário. 8 Conclusão. Referências.

\section{INTRODUÇÃO}

Inovar tem sido a palavra de ordem no Judiciário brasileiro, em todos os seus ramos. Uma urgência permanente cerca a convicção de que é preciso mudar, romper padrões, reestruturar, redirecionar a força de trabalho, questionar opções e rumos.

E muitas foram as mudanças implementadas, em grande medida direcionadas ao objetivo de tornar mais eficiente, mais efetiva, mais acessível e mais isonômica a prestação da tutela jurisdicional. Especialização de varas, aumento dos quadros de servidores e magistrados, procedimentos mais céleres, desenvolvimento e uso de novas tecnologias, implementação de ferramentas estatísticas para monitoramento da produtividade, programas de formação e aperfeiçoamento de magistrados e servidores, investimentos em gestão de pessoas e de processos, são apenas alguns exemplos das muitas alterações pelas quais vem passando o Judiciário. 
As transformações que ocorreram desde a criação do Conselho Nacional de Justiça foram fundamentais e conduziram a esse momento em que outras reflexões se fazem necessárias. Viveu-se um longo período de autoconhecimento, identificação de grandes desafios de gestão, definição, execução e monitoramento de metas, desenvolvimento de tecnologias, entre outras grandes novidades, que levaram a importantes aperfeiçoamentos nos processos de trabalho.

É suficiente, porém, aumentar a capacidade de produção e tornar mais racionais e eficientes os procedimentos judiciais e mais previsíveis os resultados? É isso que a sociedade espera do Poder Judiciário? É isso que magistrados e servidores consideram ser sua missão?

Se a capacidade de produção, de magistrados e servidores, fosse, por si só, reveladora dos resultados de sua atuação perante a sociedade, o volume de casos judiciais novos talvez não continuasse crescendo a cada ano, como vem ocorrendo, aumentando a dependência do Judiciário para o equacionamento de questões cada vez mais variadas, a revelar uma transferência à jurisdição substitutiva de um número crescente de conflitos e, em consequência, uma renúncia ao exercício de autonomias por particulares, agentes públicos e instituições.

A questão que se coloca, atualmente, é sobre motivação e finalidade para mudanças. Trata-se de indagar por que e para que inovar. Transformar por qual razão? Transformar para alcançar o quê? Em que condições uma inovação trará bons resultados? Para quem?

Mantidos os motivadores e objetivos historicamente perseguidos e até hoje implementados, os resultados da atuação jurisdicional não serão muito diferentes; talvez mais rápidos, mas pouco transformadores.

O momento é de vestir novas lentes, exige mais que prospecção de caminhos. Demanda uma busca e um alinhamento de propósitos quanto ao Judiciário que se quer.

Novas perguntas talvez precisem ser formuladas. Em lugar de se questionar como fazer melhor, de forma mais precisa e rápida cada tarefa, é necessário indagar se os resultados desse trabalho têm sido transformadores, não como fins em si mesmos, mas como instrumentos de transformação e de pacificação das relações sociais: afinal, por que e para que atua o Judiciário?

É importante, para além da inovação em si, trazer o inovador, seus valores, seus pressupostos, seus objetivos, para o cerne do processo de 
inovação. Avaliar que uso se poderá fazer da inovação, que impactos diretos e indiretos serão produzidos, se esses efeitos são compatíveis com os propósitos da instituição em que se está intervindo.

Este artigo, que coincide, no tempo, com a instituição da Política de Gestão da Inovação no Poder Judiciário, pelo Conselho Nacional de Justiça, pretende oferecer, para futuras reflexões, uma perspectiva sistêmica para orientação dos processos de inovação no Judiciário, tendo presentes, para tanto, as interconexões entre os muitos elementos e desafios a considerar, e a necessidade de uma reflexão e de algum alinhamento interno sobre propósitos e resultados esperados ou possíveis para a sociedade.

A metodologia adotada será a pesquisa bibliográfica de referenciais teóricos relacionados ao pensamento sistêmico e à filosofia da inovação, identificando-se a aplicabilidade dos respectivos conceitos e princípios aos atuais desafios do Poder Judiciário, com a consequente propositura de uma estrutura a ser observada pelos diversos órgãos judiciais nos seus processos de inovação.

\section{O QUE SIGNIFICA INOVAR?}

Tudo aquilo que exista a partir da intervenção humana consciente é invenção, criação, novidade. Vive-se em simbiose com o novo. A lição é de Ashton (2016, p. 27), que alerta que basta escutar para que se ouça a criação.

Há muitas definições para inovar.

Pavie, Sholten e Carthy (2014), inspirados em Trott (2012), acreditam que a inovação parte de uma invenção básica, que precisa se manifestar em uma atividade comercial e prover valor (financeiro, social ou ambiental) para a organização.

Grande parte das definições de inovação, disponíveis atualmente, são recolhidas de autores que pesquisam sobre economia e marketing, cujo olhar dirige-se essencialmente à iniciativa privada.

Daí ser necessária uma definição que, sem deixar de buscar referências naqueles que mais refletem e pesquisam sobre o tema, seja aplicável ao serviço público e, para o que aqui interessa, ao Poder Judiciário. 
Do conjunto dessas referências, buscando extrair seus elementos mais presentes, talvez se possa estabelecer que inovar é transformar ou transformar-se, a partir de uma ideia, agregando algum valor importante no processo. E é preciso que esse valor seja percebido por algum grupo.

A grande distinção parece encontrar seu ponto de inflexão no que possa ser considerado agregar valor. E aqui são especialmente valiosas as reflexões de Moore (1994), que partem de alguns questionamentos, como: qual o objetivo dos que atuam e são gestores do setor público? O que se espera que eles produzam? Como sua performance pode ser mensurada? O autor propõe que tais questões sejam respondidas sob perspectivas prática e filosófica.

Defende ele que o objetivo é criar valor público, o que pode não ser simples de entender, considerando que em muitas sociedades, especialmente as que mais defendem a livre-iniciativa, o Estado é visto como um mal necessário, uma instituição que serve para conter os cidadãos, em nome do convívio possível, e não para agregar. Dificilmente se percebe o Estado como uma instituição que cria valor. (MOORE, 1994, p. 297)

Por outro lado, os que atuam no setor público conhecem o valor de suas funções e sabem que a sociedade conta com eles.

A dificuldade é saber o que significa valor público, ou tomá-lo exclusivamente como o resultado positivo em uma mera relação de custo-efetividade, tendo por referência um dado objetivo estabelecido ao início de um processo de mudança. É necessário considerar a forma como os destinatários afetados por essa mudança a percebem, de dar valor ao valor que eles reconhecem (ou não) ter sido agregado ao contexto ou ao serviço anterior.

É fundamental avaliar os programas e as ações do Estado colocando na balança a satisfação dos cidadãos, de um lado, e os objetivos e as metas, prévia e tecnicamente estabelecidos, de outro. Para agregar valor público às suas iniciativas, os gestores e servidores públicos devem buscar não apenas cumprir metas, mas avaliar se os resultados satisfazem as necessidades dos usuários e destinatários dos serviços que prestam.

Importante sopesar, porém, que a atuação do Estado não se resume a prestar serviços de forma individualizada. Inúmeras funções exercidas não significam benefícios diretos e outras são materializações 
da autoridade do Estado, ao exercer poder de polícia, limitando direitos em favor da satisfação de interesses mais remotos e menos mensuráveis. Daí que, segundo Moore, muito do valor de alguns organismos governamentais não está na satisfação dos clientes finais que atendem, mas no reconhecimento, pelos cidadãos e administradores políticos e judiciais, da retidão de suas operações. (MOORE, 1994, p. 302)

Transpondo para a realidade do Poder Judiciário, é insuficiente aperfeiçoar procedimentos, investir em tecnologia e depois avaliar se metas de produtividade foram cumpridas. É preciso saber se esse cumprimento teve impactos transformadores positivos para a sociedade, que sejam consentâneos com o propósito para qual existe o Judiciário. As metas, tal como a tecnologia, não são fins em si mesmas.

Assim, recolhendo dessas referências teóricas os elementos que mais distinguem a inovação - transformação, ideia, adição de valor (público), relevância e percepção de um grupo, e avaliando-se sua aplicabilidade à realidade do Poder Judiciário e do sistema de justiça, propõe-se uma definição:

Inovar é transformar um serviço ou um ambiente/ contexto a partir de uma ideia que, executada, produza resultados sociais, políticos, econômicos ou jurídicos relevantes, positivos e sustentáveis, sob a perspectiva dos interessados e da sociedade, na efetivação da missão e dos desafios do Poder Judiciário.

A definição proposta, além de estender o olhar sobre os processos internos de trabalho e sobre as muitas formas e aspectos da prestação de serviços aos jurisdicionados, contém a preocupação com as expectativas dos jurisdicionados e demais interessados, inclusive internos, e com o propósito da atuação do Poder Judiciário, distinguindo a inovação de iniciativas que, embora possam modificar a forma como se presta o serviço, não trazem consigo valor público.

Ao definir inovação, o Conselho Nacional de Justiça a vincula à geração de valor para o Poder Judiciário e, entre os princípios da inovação, lança o olhar para a qualificação do acesso à justiça, trazendo o usuário para o eixo central da política, a ser desenvolvida mediante ampla participação dos atores internos e externos, com visão multidisciplinar, colaboração, promoção do desenvolvimento humano, acessibilidade, sustentabilidade socioambiental, desenvolvimento sustentável, desburocratização e transparência. 
A inovação é comumente classificada em incremental ou disruptiva, embora alguns autores, como Pavie (2020), diferenciem entre inovação disruptiva e paradigmática - aquela que romperia com paradigmas, como a invenção da roda.

Incremental será a inovação, sempre que implicar uma transformação de um produto, serviço ou contexto, sem mudar suas características básicas.

A inovação disruptiva não é apenas mais radical que a inovação incremental, ela muda de tal forma o produto ou o serviço que tende a alcançar um novo universo de interessados, provocando mudança de contexto de tal forma que a solução anterior se torna obsoleta.

Há mudanças de caráter disruptivo ou mesmo incremental, cujos efeitos, embora aparentemente positivos, quando considerados no seu conjunto, são deletérios ao propósito maior do sistema em que a alteração foi introduzida.

\section{INOVAR É SEMPRE BOM?}

Em 6 de agosto de 1945, a humanidade foi apresentada a uma inovação paradigmática, capaz de alterar o curso da história. Numa manhã como qualquer outra, pessoas andavam pela rua de sua cidade em suas atividades diárias quando avistaram um facho de luz brilhante no céu, seguido de um estrondo. Pouco depois, entre 70 e 80 mil pessoas estavam mortas, e outras 70 mil feridas. Naquela manhã, a bomba atômica havia sido lançada sobre Hiroshima, matando quase 30\% da população da cidade. A fissão nuclear, que pode servir à produção de energia e também a aplicações médicas, havia sido descoberta apenas poucos anos antes, em 1938, pelos químicos alemães Otto Hahn e Fritz Strassmann. Ela também serviu à construção da bomba atômica, que, com imenso poder destrutivo, inaugurou um novo paradigma para os conflitos mundiais.

Hoje em dia, várias inovações prometem grandes progressos à humanidade, do carro elétrico - desenvolvido para substituir os veículos movidos a combustíveis fósseis - aos novos modelos de smartphones e touch screens; dos sistemas de inteligência artificial aos assistentes virtuais e robôs. Disruptivas ou incrementais, tais inovações são aclamadas em nome do desenvolvimento e do crescimento econômico. 
Entretanto, raramente se olha para tais inovações de diferentes ângulos, tendo em vista suas consequências sistêmicas?.

As baterias dos carros elétricos, por exemplo, que vêm sendo desenvolvidas como uma alternativa limpa, utilizam minerais cuja mineração traz sérios riscos ao meio ambiente. Dados recentes da UNCTAD revelam, por exemplo, que a mineração de lítio e outros minérios no Salar de Atacama, no Chile, consumiu 65\% da água existente, causando depleção dos lençóis freáticos, contaminação do solo e outras formas de contaminação ambiental, impondo à população local a necessidade de deixar suas moradias. Igualmente, revela que na mineração de cobalto no Congo, país que possui quase 50\% das reservas daquele mineral, e é responsável por mais de $2 / 3$ da produção global, há aproximadamente 40 mil crianças trabalhando em condições de alta periculosidade. Somem-se a isso os riscos ambientais gerados pelo ácido sulfúrico, que pode resultar da mineração do cobalto, podendo devastar rios e destruir a vida aquática por centenas de anos. (UNCTAD, 2020)

E o que dizer da mineração de terras raras, essencial à produção de touch screens? Em Baotou, na China, é possível avistar o maior lago artificial de lixo tóxico do mundo, com $8,8 \mathrm{~km}$ de diâmetro, produto da mineração de terras raras. Além disso, as condições de trabalho nas minas de terras raras são altamente insalubres. Entretanto, em 2020, o mundo ainda descartou mais de seis milhões de toneladas métricas de lixo correspondente a monitores e telas, e as políticas de reciclagem ainda não são suficientes a fazer frente a tal volume. Ainda assim, poucos consumidores levam em consideração toda a cadeia de produção e descarte - as consequências sistêmicas - ao se deparar com um novo smartphone disponível no mercado. Pergunta-se, porém: aquele que lança um novo produto ou serviço, seja ele privado ou público, não deveria ter responsabilidade pelas consequências sistêmicas de sua inovação?

Inovação, hoje em dia, é a palavra de ordem no governo. Em 2019, vários países - inclusive não membros, como o Brasil - adotaram, no âmbito da Organização para a Cooperação e o Desenvolvimento Econômico (OCDE), a Declaração sobre Inovação no Setor Público. A declaração incentiva a inovação como forma de resolver desafios complexos, para que os governos possam continuar a bem servir a sociedade. (UNCTAD, 2019)

Veja-se, por exemplo, dados da UNCTAD sobre consequências sociais e ambientais da mineração de terras raras e minérios para produção de baterias de lítio. (UNCTAD, 2020) 
No Brasil, várias esferas do serviço público vêm abraçando a ideia da inovação, e não foi diferente com o Poder Judiciário. Há diversas iniciativas nos tribunais de Norte a Sul do país, destacando-se os laboratórios de inovação - centrais à política de gestão da inovação recentemente aprovada pelo CNJ - que vêm sendo implantados para criar um ambiente propício a estimular a inovação em uma estrutura historicamente caracterizada pela hierarquia, com pouco espaço à criatividade.

O crescente interesse em inovação no âmbito do Poder Judiciário brasileiro é, sem dúvida, altamente positivo, especialmente quando, como acima referido, abre caminho a uma mudança na cultura das relações de trabalho, proporcionando espaços de maior horizontalidade, possibilitando a ideação e o desenvolvimento de serviços com foco nas necessidades dos cidadãos.

Porém, é certo que esse crescente interesse em inovação também tem gerado euforia inovatória no âmbito do Poder Judiciário brasileiro. Percebe-se certa confusão entre "inovação" e desenvolvimento ou utilização de ferramentas tecnológicas, como se inovação necessariamente envolvesse tais práticas. A percepção da velocidade com que ocorrem as mudanças nos mais variados setores da sociedade tende a gerar um fenômeno identificado como Fomo (fear of missing out).

Aliada ao Fomo coletivo, a euforia inovatória pode gerar soluções que nem sempre atendam aos usuários e aos próprios integrantes do Judiciário da melhor forma. Devido à velocidade com que as ações são tomadas, há pouco tempo para uma maior reflexão sobre as consequências sistêmicas do que vem sendo lançado. Além disso, corre-se o risco de se adotarem soluções focadas no aumento da produtividade numérica, e não necessariamente na geração de transformação social.

Para Xavier Pavie (2020), o conceito de inovação deve ser "(re) pensado" e substituido pela ideia de non-standard innovation. Por meio da filosofia crítica, Pavie (2020) defende que (re)pensar o conceito de inovação é uma necessidade imperativa, ao menos se quisermos preservar um modo de vida autenticamente humano, o que não é uma obrigação, mas sim uma escolha. Segundo ele, "é imperativo que nos perguntemos o que queremos para nosso futuro como seres humanos". Ao que ele mesmo responde, dizendo que "se queremos a preservação 
ou o desenvolvimento da humanidade, então certamente precisamos revisar a inovação a todo custo".

Pavie (2020) propõe que se substitua o próprio conceito de inovação, tendo em vista que o significado de "inovação" contém uma ideia de algo intrinsecamente bom, o que impede que se faça um juízo crítico a cada momento sobre a real necessidade de cada potencial inovação e suas consequências.

O distanciamento crítico proposto pelo autor é postura salutar para reduzir o Fomo coletivo que se vê no Poder Judiciário hoje em dia, permitindo que a "euforia inovatória" seja substituída por uma reflexão sobre a real necessidade da inovação, suas consequências sistêmicas, e a melhor forma de integrar todos os potenciais envolvidos pelo problema ou as potenciais soluções, trabalhando de forma mais integrada com o objetivo de obter soluções e serviços melhores e mais legitimados dentro e fora da instituição.

A partir desse distanciamento crítico, é possível reconstruir o significado de inovação em governo, apreciando as várias dimensões em que se desdobra. Nesse sentido, a declaração da OCDE explicitamente reconhece a necessidade de pensar de forma sistêmica sobre inovação, como se pode ver de uma leitura atenta dos princípios que a ela subjazem, especialmente aqueles referidos nos parágrafos 1 e 2 dos considerandos. A declaração reconhece o papel importante dos governos em estabelecer e implementar um arcabouço político e legal para economias e sociedades sustentáveis, assim como refere que, como parte de seu trabalho para o bem comum, os governos têm, entre outras metas, os Objetivos de Desenvolvimento Sustentável. (UNCTAD, 2019)

É importante destacar que, na declaração, inovação é a implementação de algo novo ao contexto para ter impacto - uma estratégia proativa que os governos podem usar para responder, adaptar-se ou preparar-se a um contexto Vuca (volatile, uncertain, complex and ambiguous). Segundo a declaração, inovação é uma das maneiras de atingir as metas e prestar melhores serviços, ou seja, nem sempre é necessário inovar.

Inovação, portanto, não é sempre necessário, tampouco sempre bom. Não se confunde, ademais, com colocar à disposição novas plataformas ou outras ferramentas tecnológicas, tampouco com inteligência artificial ou chatbots - embora essas ferramentas sejam 
também fruto de inovação. Inovar é implementar algo novo para ter impacto, quando e se necessário, atentando para as consequências sistêmicas das ações correspondentes, e integrando os potencialmente envolvidos.

Como parte do Estado brasileiro, também ao Poder Judiciário cabe inspirar-se pelos princípios orientadores da declaração da OCDE, incorporando uma atitude mais crítica e sistêmica ao pôr em prática inovações.

\section{INOVAÇÃO RESPONSÁVEL}

Ao lado de um olhar crítico sobre a inovação, que convida à consciência de que ela não é algo intrinsicamente bom, mas que pode ser ou não bom conforme suas características em cada situação, surge o espaço para que se pense em inovação responsável. Se a inovação não é necessariamente boa, certamente deve ser sempre responsável, o que significa que aquele que inova não pode deixar de considerar os diversos impactos de sua inovação, porque, em última análise, tem responsabilidade quanto a ela.

Pavie (2014) propõe que, para fins de responsabilidade, é preciso haver uma fusão entre as esferas privada e profissional de cada administrador. Assim, segundo ele, um administrador responsável deveria se perguntar se, enquanto cidadão, ele apoiaria aquilo que, como administrador, está a ponto de implementar. O mesmo princípio se aplica aos gestores do Poder Judiciário, que devem se perguntar se, enquanto cidadãos e, em especial, jurisdicionados, considerariam adequada a inovação que se propõem a implementar.

De acordo com Pavie (2014), ainda, a responsabilidade do inovador não se limita à sua responsabilidade legal: ela vai além, e se traduz numa preocupação de "fazer o bem" ao tomar decisões quando se é responsável por outros. Ele defende, portanto, que qualquer inovação, para ser responsável, leva em conta os impactos diretos e indiretos em fatores sociais, econômicos e ambientais, tanto nos usuários e stakeholders como na sociedade como um todo. Trata-se, portanto, de integrar responsabilidade a todos os processos de inovação.

A responsabilidade na inovação, portanto, relaciona-se com um "princípio do cuidado", em que é necessário se importar, ter cuidado com o bem-estar dos demais, incluindo gerações futuras. (PAVIE, 2014) 
Não por outra razão, entre os princípios da Política de Gestão da Inovação do Poder Judiciário, estão o desenvolvimento sustentável e a sustentabilidade socioambiental.

Ainda, a inovação responsável não prescinde de uma avaliação sobre seus motivos - propósitos (PAVIE, 2014). A inovação responsável, como se discute a seguir, tem que estar em harmonia com os propósitos da instituição.

Segundo a Comissão Europeia, inovação responsável é um processo interativo e transparente, por meio do qual atores sociais e inovadores devem interagir e trabalhar em conjunto de acordo com as oportunidades oferecidas, para assegurar que questões éticas da sociedade sejam preservadas. (PAVIE, 2014)

A ideia de inovação responsável vem sendo incorporada por vários países e companhias ao redor do mundo. Por exemplo, no Reino Unido, há o reconhecimento expresso de que a inovação responsável é uma responsabilidade coletiva em que todos têm um papel a desempenhar. Embora inclua considerações regulatórias e relativas a risco, a noção de inovação responsável é mais ampla. Assim, é recomendada a utilização, de forma contínua, da abordagem Area (anticipate, reflect, engage, act) em todos os processos de inovação. (UNCTAD, 2019)

Na abordagem adotada pelo Reino Unido, chama a atenção o reconhecimento expresso de que a inovação, que pode dar lugar a questões e dilemas, é frequentemente ambígua em termos de propósitos e motivações, e imprevisível em termos de impactos, benefícios ou o contrário (UNCTAD, 2019). Desse modo, o item refletir considera a necessidade de reflexão sobre os motivos e propósitos da inovação, além de seus potenciais impactos.

Da mesma forma, a OCDE exarou uma Recomendação para a Inovação Responsável em Matéria de Neurotecnologia (ORGANIZAÇÃO PARA A COOPERAÇÃO E DESENVOLVIMENTO ECONÔMICO, 2019), consagrando a promoção do princípio da inovação responsável como um dos princípios norteadores da pesquisa na área.

A inovação responsável, como se verá a seguir, aponta para a importância de trazer para a inovação no Poder Judiciário uma perspectiva sistêmica. 


\section{INOVANDO EM PERSPECTIVA SISTÊMICA}

Quando se lida com problemas complexos, eventuais intervenções sobre elementos visíveis, por mais promissoras e inéditas que sejam, terão que considerar as interrelações desses elementos com outros, nem sempre evidentes; terão que conhecer o motivo pelo qual o sistema funciona de uma determinada forma, e prever os possíveis efeitos sistêmicos que poderão advir.

Um bom exemplo pode ser o desafio da litigiosidade ou da judicialização massiva de conflitos. Numa primeira avaliação, alguns elementos talvez despontem como sinais visíveis (exterioridades) do problema: o aumento, a cada ano, de demandas distribuídas, a elevação das taxas de congestionamento, o volume de recursos, a baixa procura por soluções consensuais ou pré-processuais, entre outros.

Há uma tendência de se tomar tais exterioridades, que são mensuráveis e por vezes tangíveis, como elementos suficientes para serem avaliados e tratados. Dirige-se o olhar para algo revelador de um sintoma de um problema, e age-se diretamente sobre ele. Aquele sintoma, porém, ainda que venha a requerer algum tratamento, poderá se revelar como a mera ponta em um jogo de varetas. Atuar diretamente sobre ela, poderá produzir consequências, nem sempre positivas, sobre um todo maior.

A adoção de soluções lineares, cartesianas, convencionais para problemas complexos, tende a perpetuá-los. É de Einstein a advertência de que os problemas significativos que enfrentamos não podem ser resolvidos no mesmo nível de pensamento em que estávamos quando os criamos. (STROH, 2015, p. 4)

O pensamento sistêmico é a chave para a abordagem de problemas complexos. E para melhor distingui-lo do pensamento linear, é necessário partir da ideia de sistema.

Meadows (2008, p. 7) define um sistema como um conjunto de elementos interconectados, coerentemente organizado de forma a alcançar um resultado.

Em sua definição, há os elementos, a interconexão entre eles, e um propósito para o funcionamento do sistema, que não necessariamente equivale ao propósito do funcionamento de cada elemento. Ela exemplifica com um time de futebol profissional, onde 
há os jogadores, a bola, o técnico (elementos); há as regras do jogo e a forma como os jogadores se comunicam, a tática orientada pelo treinador (interconexões); e há o propósito do time, que pode ser vencer o campeonato, ainda que cada jogador, eventualmente, possa ter chegado ao time com um propósito específico, como manter-se saudável, realizar uma atividade lucrativa, encontrar amigos, entre outros.

Alterar os elementos desse sistema, com a simples troca de um jogador, por exemplo, tende a não produzir mudanças significativas no seu funcionamento. Mas a mudança nas interconexões ou no propósito pode produzir transformações substanciais (MEADOWS, 2008, p. 15-16). Substituam-se as regras do jogo de futebol pelas de rúgbi, ou modifiquese o propósito, para que passe a ser diversão ou a confraternização de amigos, e a transformação, em termos de funcionamento, será bastante grande.

Não significa que os elementos do sistema sejam menos importantes que as interconexões e o propósito ou a função. Todos são relevantes. A falta de um elemento ou a sua substituição pode mudar o comportamento do sistema na medida em que essa substituição provoque alterações no propósito ou nas interconexões. Isoladamente, porém, a atuação direta sobre os elementos tende a não produzir mudanças sustentáveis no comportamento. (FERRAZ, 2020, p. 188)

Trabalhando sobre a definição de Meadows (2008, p. 5), Stroh (2015) define o pensamento sistêmico como a habilidade de entender as interconexões, de forma a atingir um propósito desejado. Segundo o autor, esta forma de pensar auxilia a compreender o propósito para o qual o sistema está funcionando, e parte do pressuposto de que os sistemas são perfeitamente desenhados para alcançar os resultados que eles normalmente alcançam, porque algum benefício ele gera para os que dele participam, não importa o quão disfuncional ele seja.

Interconexões e propósito não são evidentes como os elementos.

No exemplo da litigiosidade, tomar como suficiente, para uma intervenção, que, a despeito da produtividade, a taxa de congestionamento de processos vem tendo pouca oscilação (exterioridades), e atuar sobre essa taxa, criando uma meta de julgar mais processos, por ano, do que o número de processos novos distribuídos, não tem resultado em mudança significativa no fenômeno. 
O aumento de ações novas é apenas um dos sintomas de litigiosidade, um fenômeno mais complexo, multicausal e multifacetado, que as estatísticas são capazes hoje de captar (o que foi um grande avanço), mas que não explicam. Aumentar, sistematicamente, a produtividade, como resposta, assim como ampliar o número de juízes e servidores, ou criar alguns embaraços para o ingresso de novas ações, não apenas não muda o comportamento do problema, por sua característica sistêmica e complexa, como pode torná-lo ainda maior.

Um dos exemplos é o chamado paradoxo da eficiência², conhecido como efeito bumerangue: o aumento da eficiência no uso de determinados serviços ou produtos resulta em uma maior demanda por eles. O uso eficiente contribui para aumentar o consumo.

Outro exemplo é a constante modificação de elementos específicos, como remédio, por excelência, para alcançar melhores resultados: substituem-se pessoas em funções consideradas estratégicas, modificam-se disposições legislativas, criam-se novas soluções tecnológicas. Os resultados iniciais, muitas vezes, parecem ser promissores, mas um dos padrões de funcionamento dos sistemas, que decorre de sua complexidade, é que, diante de uma intervenção, o comportamento tende a melhorar antes de piorar. $O$ alívio dos sintomas faz pensar que o problema foi resolvido, visto que o feedback, o fluxo de influência entre as ações e os resultados, pode chegar com alguma defasagem, e os sinais de prejuízo tendem a ser percebidos apenas no longo prazo. (SENGE, 2017)

Daí a importância de conceber mecanismos para leitura de resultados ao longo de todo o processo e sob diversos ângulos. Ver um filme em 3D, em vez de várias fotos. Trabalhar com tendências e sem expectativa de resultados diretos ou definitivos.

Talvez, aqui, seja necessário formular perguntas mais abrangentes: por que se busca, com tanta insistência, a atividade judicial substitutiva? Por que se a leva às últimas consequências? Que efeitos indiretos podem advir de uma intervenção?

Inovar no Poder Judiciário, criando soluções inéditas para os problemas complexos, mais que boas intenções, portanto, deve considerar essa complexidade, seus princípios operadores e os padrões de funcionamento dos sistemas. A abordagem deve ter em conta as

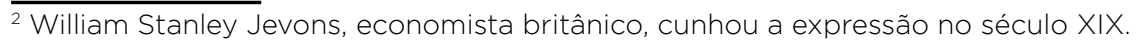


interconexões entre diversos fenômenos, e entre esses, seus sinais exteriores e suas ligações não aparentes.

Será preciso presumir que não há apenas uma solução, muito menos uma solução definitiva, o que exigirá constante monitoramento, aprendizagem, e ajustes de rota.

Há, porém, na lição de Senge (2017, p. 397), mudanças pequenas ou concentradas, muitas vezes imperceptíveis, que podem produzir grandes resultados. Trata-se do princípio da alavancagem.

Um dos desafios, para o inovador, ao abordar um problema complexo, é identificar onde estão os pontos de alavancagem. Eles não são óbvios e, não raras vezes, estão distantes dos sintomas exteriores do problema. Uma vez conhecidos, em seus fluxos e nas relações entre seus elementos, é possível identificar certeiras possibilidades de mudança que, feitas de forma precisa, podem produzir efeitos sistêmicos, em movimentos espiralares. (FERRAZ, 2020, p. 220)

\section{A ESPIRAL DA INOVAÇÃO NO PODER JUDICIÁRIO}

Para a abordagem de problemas complexos, convém que as ações que se pretendem responsavelmente inovadoras tenham em conta os princípios operadores da complexidade, identificados por Morin (2005): o princípio da recursividade, o hologramático e o dialógico.

primeiro pressupõe que um mesmo fenômeno pode ser causa e consequência, produto e produtor de efeitos (MORIN, 2005, p. 61). A relação entre o homem e a cultura é um bom exemplo desse princípio em funcionamento: o homem é forjado por sua cultura, e também a constrói.

A representação desse movimento é uma espiral. Senge (2017, p. 137) defende que a realidade é constituída de círculos, mas as pessoas tendem a ver linhas retas, por serem condicionadas ao pensamento linear, que sempre sugere uma relação de causalidade direta entre os acontecimentos. $\bigcirc$ pensamento sistêmico introduz a ideia de que há fluxos recíprocos de influência. Ao traçar esses círculos, será possível ver os padrões que se repetem continuamente, decidindo como intervir, com algum grau de previsibilidade. 
O princípio hologramático é o que trata da relação entre as partes e o todo em um fenômeno e que explica que não é possível abordar um sistema complexo segundo a alternativa do reducionismo (que quer compreender o todo partindo apenas das qualidades das partes), nem do holismo, que, segundo Morin, não é menos simplificador, ao negligenciar as partes na tentativa de compreender o todo. O todo estará nas partes e as partes estarão no todo.

Esse princípio desconstrói a ideia de que o todo sempre será equivalente à soma das partes, e admite que poderá ser maior ou menor, a depender da existência ou não de sinergia na relação entre as partes e entre essas e o todo. Uma equipe de trabalho poderá ter um desempenho maior ou menor que a soma das capacidades individuais dos seus integrantes, a depender, para além das potencialidades individuais, da capacidade de trabalho integrado e alinhado.

A ideia de que a parte está no todo e o todo está na parte traz consigo a importância de não se enxergar um problema como algo externo ao grupo. A chave, segundo Stroh (2015, p. 5), é ajudar os participantes a cultivarem uma profunda atenção à realidade como algo que eles mesmos criaram, em vez de algo que existe do lado de fora e independentemente deles.

Quanto ao princípio dialógico, trata da noção de complementaridade, da combinação e convivência entre situações aparentemente antagônicas ou dicotômicas. É o princípio que assume a contradição, para além da ideia de tese, antítese e síntese, que pressupõe que antagonismos podem ser estimuladores e reguladores, buscando restabelecer as articulações entre o que foi separado, compreender a multidimensionalidade, não esquecer as totalidades integradoras. (MORIN, 2005, p. 190)

O pensamento sistêmico, que se caracteriza, a um só tempo, como um novo mindset e uma abordagem transdisciplinar de resolução de problemas, é capaz de lidar com a complexidade inerente aos problemas relacionados à sociedade. (RUSSEL, 1974)

Presentes esses pressupostos, talvez se possa conceber algumas diretrizes para a inovação responsável, na busca de dar tratamento a problemas de maior complexidade. 
A imagem de uma espiral, aqui, contribui para a compreensão das interrelações entre os diversos aspectos e etapas do processo de inovação e da importância de se inovar com um propósito.

A espiral traz a ideia de entrelaçamento de elementos, a partir de um eixo, que, ao influxo de um ou mais fatores, impulsiona-se e ao ambiente à volta, num movimento recursivo que ganha vida própria. Remete à ideia de interdependência, de diferentes estágios de força e alcance, de incertezas, de continuidade, de limites pouco definidos e, paradoxalmente, a uma espécie de coerência, como num caos ordenado. Os elementos captados por uma espiral têm perspectivas diferentes do todo das suas relações com ele e os demais elementos. Perceber todo o seu espectro e seus padrões de funcionamento requer a adoção de uma perspectiva suficientemente distanciada no tempo e no espaço.

No movimento espiralar, estarão gravitando e poderão ser captados os sintomas dos problemas que afetam o funcionamento do todo. Também nele estarão os elementos do sistema, interconectados e atuando, conforme suas funções ou propósitos. Em qualquer lugar dessa espiral, poderão surgir ideias que, trabalhadas sob perspectiva sistêmica - o que significa ter em conta seus padrões de funcionamento e seu propósito -, podem se transformar em inovações, produzindo valor para o todo.

No eixo da espiral talvez estejam as próprias causas dos problemas, bem como o propósito do funcionamento do sistema, porém, aqui se aplica, também, a ideia do holograma, a lembrar que cada parte carrega em si o todo e que o todo também estará nas partes, daí a importância de se estar atento aos sinais, que talvez possam ser captados mais facilmente na periferia do que no centro da espiral.

A inovação, como examinado acima, pressupõe agregar valor ao contexto no qual ela se insere. No setor público, esse valor deverá estar conectado a um propósito maior para o qual funciona ou deve funcionar o Estado, enquanto sistema, e seus muitos órgãos e entidades, que nada mais são do que subsistemas de um todo maior.

Um dos aspectos mais frustrantes no funcionamento dos sistemas e subsistemas, segundo Meadows (2008, p. 15), é que os propósitos dos seus muitos elementos nem sempre estarão alinhados ao do todo, o que poderá conduzir a um comportamento, no geral, indesejado por todos. Isso não significa que todos os elementos devam ter o mesmo propósito ao integrarem-se ao sistema, nem que haja uma deliberada 
atuação para que não se alcance a função para a qual o sistema existe. Ainda que todos os players concordem que um determinado problema complexo precise ser resolvido, agindo sob propósitos muito diferentes, eles encontrarão muita dificuldade para erradicá-lo.

Ninguém deliberadamente cria taxas de congestionamento altas no Poder Judiciário. Conectem-se muitos propósitos, porém, e o problema se instalará, e de forma resistente.

Pessoas que se sentiram prejudicadas no exercício de algum direito, e que não conseguem resolver consensualmente seus conflitos; advogados buscando mercado de trabalho para atuar; facilidades criadas para dar acesso à justiça, como a gratuidade judiciária; magistrados e servidores que trabalham até encontrarem os limites de suas forças; estruturas e tecnologias que foram projetadas para determinados objetivos; alterações legislativas que estabelecem novos procedimentos obrigatórios; tribunais superiores que decidem, no tempo possível, nem sempre adequado, relevantes questões de direito.

Os propósitos que conduzem cada um desses fatores não são intrinsecamente ruins, mas, considerados no seu conjunto, acabam por produzir resultados indesejados para o sistema, no caso acima, as altas taxas de congestionamento.

Assim, será importante que se busquem alinhamentos, não para que cada elemento tenha que abdicar do seu propósito, mas para que todos os fatores atuem de forma a favorecer o propósito maior do sistema.

A identificação do propósito de um sistema não é algo simples. Quase nunca há uniformidade, mas talvez seja possível buscar alguns consensos.

O que seria esse propósito de atuação do Poder Judiciário?

Com certeza, não é a redução das taxas de congestionamento. Estas apenas indicam alguma disfuncionalidade no sistema.

A pergunta a ser feita gira em torno da razão de ser da existência do Judiciário e de todo o sistema de justiça. E qual seria ela? Preservar bens jurídicos fundamentais? Garantir e impor direitos? Dar a cada um o que é seu? Evitar a justiça privada? Garantir segurança jurídica? Dizer o direito no caso concreto? Preservar o pacto social? Todas as anteriores? 
Essas foram, são e serão, sem dúvida, funções importantes a justificar a existência de um sistema de justiça e estão relacionadas aos próprios fins da justiça, à luz das várias correntes da filosofia.

No entanto, considerando seu grau de indeterminação, talvez seja importante buscar referências mais concretas, que permitam visualizar, com algum grau de consenso, pelo que atua ou deve atuar o Poder Judiciário. A Constituição parece ser o marco seguro.

Os órgãos e as instituições do sistema de justiça integram o Estado, o qual, nos termos do preâmbulo da Constituição brasileira, está destinado a assegurar o exercício dos direitos sociais e individuais, a liberdade, a segurança, o bem-estar, o desenvolvimento, a igualdade e a justiça como valores supremos de uma sociedade fraterna, pluralista, sem preconceitos, fundada na harmonia social e comprometida com a solução pacífica das controvérsias.

Promover a justiça, a igualdade, a harmonia, a solução pacífica de conflitos, são funções que, dentre as do Estado, talvez sinalizem para o real propósito da atuação de um sistema de justiça.

Trata-se de propósito que está alinhado com o ODS 16, das Nações Unidas. Este Objetivo de Desenvolvimento Sustentável, que integra a Agenda 2030, prevê que cabe aos Estados-parte a promoção de sociedades pacíficas e inclusivas para o desenvolvimento sustentável, proporcionando o acesso à justiça para todos e a construção de instituições eficazes, responsáveis e inclusivas em todos os níveis.

O Poder Judiciário comprometeu-se com a Agenda 2030 da ONU, através da Meta 9, da estratégia nacional, que pretende a integração das ações de todos os tribunais aos objetivos de desenvolvimento sustentável da referida agenda.

\section{DESENHANDO A ESPIRAL DE INOVAÇÃO NO PODER JUDICIÁRIO}

A partir das bases teóricas expostas, cabe propor uma abordagem para orientar os processos de inovação no Poder Judiciário. Inspirada nas abordagens de design thinking sistêmico (VAN DER BIJLBROUWER, MALCOLM, 2020), ela pretende, no entanto, demonstrar a fluidez do processo de inovação sob a perspectiva sistêmica, e por isso é representada por meio de uma espiral. 


\section{Figura 1 - Espiral da Inovação}



A escolha da espiral objetiva trazer constantemente à lembrança a necessidade de atentar para os impactos sistêmicos ao longo de todo o processo de inovação. Dessa forma, não se trata de uma receita fixa a ser seguida às cegas, ou sem crítica, mas de um convite ao estar consciente de tais impactos em todos os momentos.

Segundo Pavie (2014), a inovação responsável deve-se orientar por três grandes questões: 1) toda necessidade deveria ser atendida? 2) quais os impactos e consequências diretos da inovação? 3) sabemos identificar as consequências e os impactos indiretos da inovação nos estilos de vida da sociedade como um todo? Essas questões devem acompanhar todas as fases do processo de inovação, desde a captação de desafios - problemas ou oportunidades - até o monitoramento e a avaliação de resultados.

Relembre-se que, para ele, a inovação responsável deve levar em consideração os impactos diretos e indiretos em fatores sociais, econômicos e ambientais, tanto nos usuários e stakeho/ders como na sociedade como um todo (PAVIE, 2014). Orienta-se pelo princípio do cuidado, e imprescinde de uma avaliação sobre propósito.

\footnotetext{
$\overline{3}$ A arte da Espiral da Inovação foi desenvolvida pela designer Karen Schilling Ferraz.
} 
Além das dimensões acima, é importante que se tenha em mente, ao pensar de forma sistêmica sobre inovação, a dimensão cultural. Esta dimensão representa os valores, o legado, o pertencimento, e não se pode pensar em inovar sem pensar em cultura.

A cultura impacta desde a viabilização da inovação, na medida em que é preciso que a primeira estimule e possibilite a última, como também durante todo o processo e na implementação da inovação. Muitas vezes, inovações não são postas em prática justamente porque a cultura a elas resiste, configurando um verdadeiro "sistema imunológico" que bloqueia novas ideias, novos processos e serviços. Por esse motivo, diz-se que não existe transformação digital sem transformação cultural.

De acordo com as diretrizes da OCDE, que recomenda uma abordagem de portfólio para a inovação, os processos de inovação devem ser permanentes e contínuos nos órgãos de governo. Neste ponto, os laboratórios de inovação têm papel crucial para fomentar uma cultura de inovação dentro do Poder Judiciário, permitindo o surgimento de iniciativas de diversas origens. (COELHO et al., 2019)

Nesse diapasão, é imprescindível que existam canais de comunicação aptos a captar ideias, sugestões, propostas, relatos de problemas ou oportunidades, de forma permanente. Tais canais de comunicação servem também a trabalhar a cultura, permitindo que as inovações sejam adequadamente compreendidas, e que passem realmente a fazer parte da instituição.

Ademais, é fundamental que todo o processo de inovação seja orientado pelo propósito do Poder Judiciário, ainda que outros propósitos possam também ser levados em conta na medida em que compativeis com aquele. Aqui, importa referir que este propósito deveria inspirar e orientar de forma permanente a cultura nos serviços judiciários, e para tanto deveria ser constantemente trabalhado dentro da instituição. As perguntas por que e para que inovar, presentes em cada novo desafio - problema ou oportunidade - não podem ser respondidas adequadamente sem que haja clareza quanto a esse propósito em toda a instituição.

Identificado um potencial problema ou uma oportunidade de melhoria - um desafio -, deve-se fazer uma pré-seleção de stakeholders, considerando inclusive aqueles que estão na periferia do sistema e poderiam ser potencialmente atingidos. 
A seguir, juntamente aos stakeholders pré-selecionados, deve-se proceder à definição do problema ou da oportunidade de melhoria que se quer priorizar.

$\mathrm{Na}$ sequência, os múltiplos stakeholders deverão mapear o sistema, gerando um mapa com os atores e as partes interconectadas (OSPINA, 2018), considerando também a periferia.

$\mathrm{Na}$ fase seguinte, devem-se identificar os pontos de intervenção que terão maior alavancagem, com menos impactos negativos (OSPINA, 2018). Essa definição deve ser feita de forma crítica, levando em conta o propósito da instituição.

Em se tratando de desafios complexos, é possível que haja várias perspectivas quanto a eles, conduzindo a soluções diversas. Conforme acima referido, alterando-se as interconexões ou o propósito, altera-se o sistema. Dessa forma, é importante que se projetem as consequências de optar por uma ou outra perspectiva, e fundamental a consciência do propósito institucional também para a escolha da perspectiva a ser trabalhada, caso essa escolha se faça necessária. As consequências, conforme anteriormente mencionado, consideram fatores sociais, econômicos e ambientais, tanto relativamente a usuários e stakeho/ders quanto à sociedade como um todo.

Igualmente, definidos o problema ou a oportunidade, é preciso reavaliar se todos os stakeholders previamente selecionados efetivamente correspondem aos potencialmente afetados pelos desafios (problemas/oportunidades) ou pelas potenciais mudanças.

A partir daí, sugere-se que se passe à ideação e à prototipagem. Uma vez colocada em prática a inovação, ela deverá ser monitorada e avaliada, não apenas com relação a seus impactos diretos, mas também indiretos.

No que diz respeito ao monitoramento e à avaliação, importa evitar que quem quer que seja "se apaixone" por uma determinada inovação, porque isso pode cegar o olhar para impactos negativos daquela inovação, como também criar resistências a novas mudanças. É importante que se compreenda que o processo de inovação é contínuo, que deve corresponder às necessidades trazidas pela realidade, que muitas vezes exige respostas rápidas a situações emergentes, deixando de lado inovações que já não são capazes de atendê-las. 
A abordagem pretende, portanto, que durante todo o processo de inovação, exista um acompanhamento permanente da adequação da inovação aos propósitos do Poder Judiciário, bem como de suas consequências e seus impactos diretos e indiretos. É fundamental lembrar que esses impactos são de três ordens - social, econômica e ambiental - e devem ser avaliados com relação aos usuários, stakeho/ders e à sociedade como um todo. Em síntese, trata-se de se perguntar a todo momento se a inovação traz benefícios que justificam os custos sistêmicos, e se ela está de acordo com o propósito institucional.

\section{CONCLUSÃO}

Há um movimento positivo no Poder Judiciário brasileiro no sentido de inovar e aprimorar os serviços oferecidos aos jurisdicionados. Entretanto, esse movimento ainda se funda no conceito de inovação como algo intrinsicamente bom, e não incorporou aos processos de inovação a avaliação de seus impactos sistêmicos e de sua adequação ao propósito institucional.

A partir de uma reflexão sobre os processos de inovação no Poder Judiciário com base em uma perspectiva da filosofia crítica aliada à ideia de inovação responsável, este artigo oferece uma abordagem sistêmica para orientação dos processos de inovação no Judiciário.

Nessa abordagem, baseada na metodologia do design thinking sistêmico e inspirada na imagem da espiral, o inovador e aquele que implementa a inovação devem, em todos os momentos do processo de inovação, avaliar os impactos e as consequências daquela, de ordem social, econômica e ambiental, sobre os usuários, stakeho/ders e a sociedade como um todo. Devem, ademais, avaliar a todo momento a adequação da inovação ao propósito institucional.

Com tal abordagem, busca-se dar sentido à inovação, para que sirva à construção efetiva de uma sociedade pacífica e inclusiva, e para o desenvolvimento sustentável. 


\section{REFERÊNCIAS}

ASHTON, Kevin. A história secreta da criatividade. Tradução Alves Calado. Rio de Janeiro: Sextante, 2016.

COELHO, Alexandre Zavaglia et al. Inovação no judiciário: conceito, criação e práticas do primeiro laboratório de inovação do Poder Judiciário. São Paulo: Blucher, 2019.

FERRAZ, Taís Schilling. Um olhar sistêmico sobre a violência no Brasil: a insuficiência dos mecanismos de controle e repressão. 2020. Tese (Doutorado em Ciências Criminais) - Pontifícia Universidade Católica do Rio Grande do Sul, Porto Alegre, 2020.

MEADOWS, Donella. Thinking in systems: a primer. Vermont: Chelsea Green Publishing, 2008.

MOORE, Mark H. Public value as the focus of strategy. Australian Journal of Public Administration, [S.I.], v. 53, p. 296-303, set. 1994.

MORIN, Edgar. Ciência com consciência. Tradução Maria D. Alexandre, Maria A. S. Dória. 8. ed. Rio de Janeiro: Bertrand Brasil, 2005.

ORGANIZAÇÃO PARA A COOPERAÇÃO E DESENVOLVIMENTO ECONÔMICO. OECD Recommendation on Responsible Innovation in Neurotechnology. [S./.], 2019. Disponivel em: https://www.oecd.org/ science/recommendation-on-responsible-innovation-in-neurotechnology. htm. Acesso em: 28 maio 2021.

OSPINA, Daniel. Beyond design thinking: the systemic design thinking framework.

[S.I.], 2008. Disponível em: https://conductal.medium.com/ beyond-design-thinking-the-systemic-design-thinking-framework8d4952271222. Acesso em: 28 maio 2021.

PAVIE, Xavier. Critical philosophy of innovation and the innovator. New Jersey: Wiley, 2020.

PAVIE, Xavier; SHOLTEN, Victor; CARTHY, Daphné. Responsible innovation: from concept to practice. New Jersey: World Scientific, 2014. 
RUSSEL, Ackoff. Redesigning the future: a systems approach to societal problems. New Jersey: Wiley, 1974.

SENGE, Peter M. A quinta disciplina: a arte e a prática da organização que aprende. Tradução Gabriel Zide Neto. 34. ed. Rio de Janeiro:

BestSeller, 2017.

SHAPIRO, Stephen. As melhores ideias são estúpidas. São Paulo: Casa das Letras, 2012.

SKILLICORN, Nick. What is innovation? [S./.], 2016. Disponível em: https://www.ideatovalue.com/inno/nickskillicorn/2016/03/innovation15-experts-share-innovation-definition/. Acesso em: 12 maio 2021.

STROH, David Peter. Systems thinking for social change. Vermont: Chelsea Greed Publishing, 2015.

TROTT, P. Innovation management and new product development. New Jersey: Prentice Hall, 2012.

VAN DER BIJL-BROUWER, Mieke; MALCOLM, Bridget. Systemic design principles in social innovation: a study of expert practices and design rationales. She Ji: The Journal of Design, Economics, and Innovation, [S.I.], v. 6, n. 3, p. 386-407, 2020.

UNCTAD. Declaration on public sector innovation. [S./.], 2019. (OECD Legal Instruments). Disponível em: https://legalinstruments.oecd.org/ en/instruments/OECD-LEGAL-0450. Acesso em: 28 maio 2021.

UNCTAD. Developing countries pay environmental cost of electric car batteries: prosperity for all. [S./.], 2020. Disponível em: https:// unctad.org/news/developing-countries-pay-environmental-costelectric-car-batteries. Acesso em: 28 maio 2021. 